\title{
不同适应状态下神经重叠复眼 接收视觉信息的模式
}

\author{
吴卫国郭爱克 马春华 石淑珍 王谷岩 吴盛立
}

(中国科学院生物物理研究所, 北京)

双翅目昆虫复眼的每一个小眼包含 8 个光感受器细胞, 其中 6 个大的外周小网膜 细胞 $\left(R_{1-6}\right)$ 为第一亚视觉系统. 6 个相邻小眼的 6 个不同的外周小网膜细膜接收视觉信息后传递 并叠加在第一视神经节的同一个弹药筒内. 另外， 2 个中心小网膜细胞 $\left(R_{7-8}\right)$ 为第二亚视 觉系统, 它接收视觉信息后直接传递到第二视神经节 ${ }^{[1-3]}$.

本篇研究的目的是探索蝇和虹复眼在不同的适应状态下， $R_{1-6}$ 和 $R_{7-8}$ 是如何接收视觉 信息的.

\section{方法}

实验动物为家蝇 (Musca domestica) 及憎黄虬* (Atylotus miser Szilady), 采用逆光照明 的深伪瞳及角膜中和技术 ${ }^{[4]}$.

\section{结 果}

\section{1. 暗适应状态下接收视觉信息的模式}

图 1 为家蝇在 30 分钟暗适应 $\left(1 \times 10^{-2}\right.$ 勒克 斯）后 7 个远端感杆的末端像 (图 1).

可以看出,此时所给出特定方向的视觉信息是由两个亚视觉系统 $\left(R_{1-6}\right.$ 和 $\left.R_{7-8}\right)$ 同时接 收的. 这个结论还可以在相同的条件下对家蝇复眼深伪瞳的观察中得出. 深伪瞳是感杆末端 像在复眼曲率中心的叠加 (图 2).

2. 中度明适应状态下接收视觉信息的模式 图 3、4、5 和 6 分别为家䗉和憎黄虬复眼 在一分钟中度明适应 $\left(25 \times 10^{3}\right.$ 勒克斯) 后远端感杆的末端像. 从这些图可以看出, 感杆 7 的 中心光点一直很明亮, 感杆 1-6 的外周光点不同程度的暗谈下来, 甚至消失, 这是由于屏蔽色 素的移动减小了感杆 1-6 的光通直径的结果. 色索移动系统的功能可能就在于控制入射到 感受器细胞上的光, 而色素的移动不仅出现在屏蔽色素细胞内, 也出现在视细胞内.

在某种情况下，某一方向的视觉信息的接收就是由部分的第一亚视觉系统和第二亚视觉 系统共同完成的 (图 3-6).

3. 在强光适应状态下接收视觉信息的模式图 7,9 分别为家蝇和憎黄虻复眼在 10 分 钟强光适应 $\left(50 \times 10^{3}\right.$ 勒克斯) 后远端感杆的末端像. 它们表明中心感杆 7 的光点一直很亮, 外周感杆 1-6 的光点已分辩不清或已消失(图 7,9).

* 虹的学名由中国科学院动物研究所王遵明同志鉴定. 


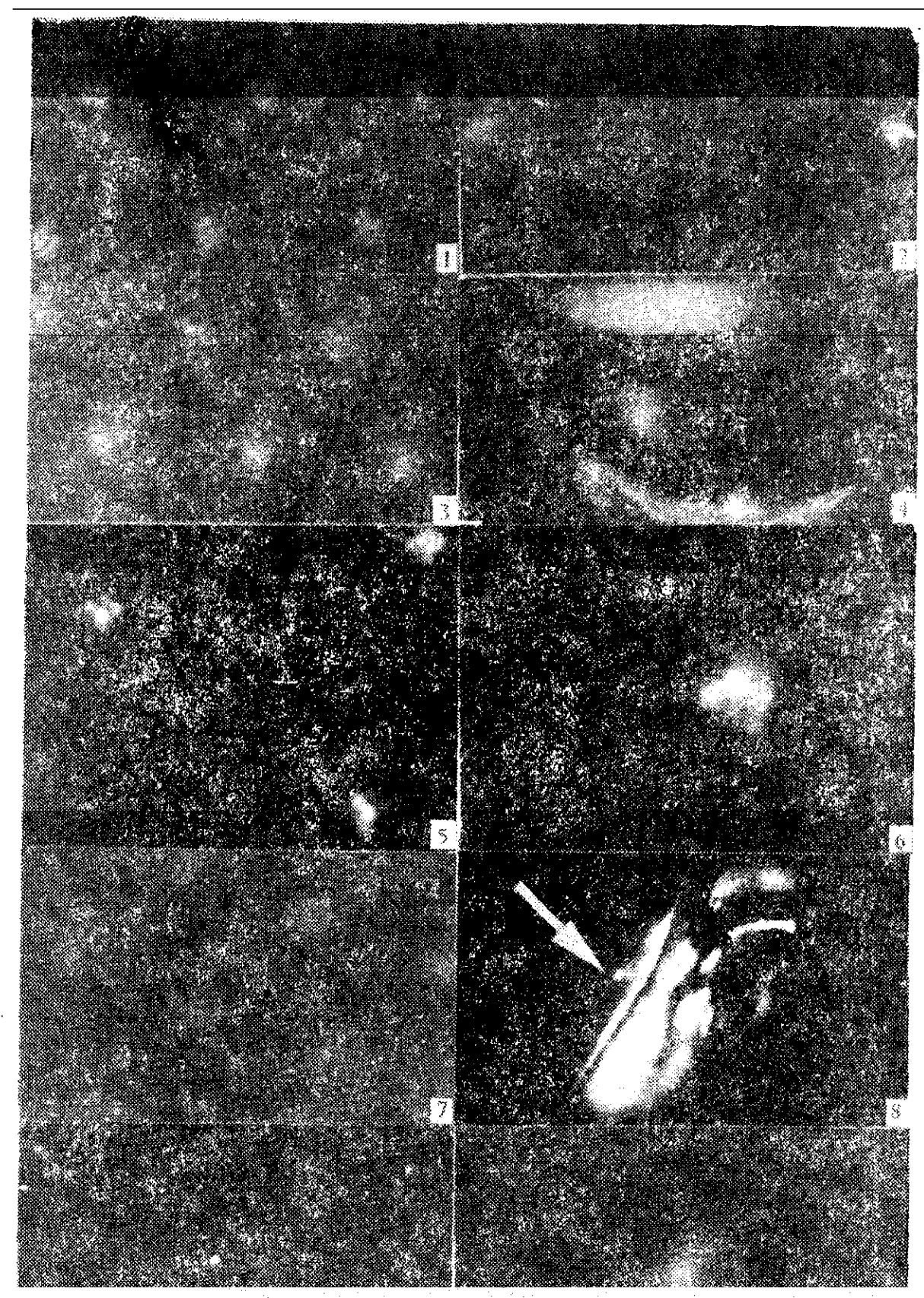

图 1 暗适应状态下家蝇复眼远端感杆末端的光点像; 图 2 暗适应状态下家蝇复眼背 区的双眼深伪瞳;图 3 中度明适应状态下家唡复眼远端感杆末端的光点像; 图 4 中度 明适应状态下家蝇复眼的深伪瞳; 图 5 中度明适应状态下憎黄虹复眼远端感杆末端的 光点像; 图 6 中度明适应状态下憎黄虹复眼的深伪瞳; 图 7 强光适应状态下家蝇复 眼远端感杆末端的光点像; 图 8 强光适应状态下家蝇复 眼 的深 伪 瞳 (箭 头 所示); 图 9 强光适应状态下憎黄虬复眼远端感杆末端的光点像; 图 10 强光适应状态下憎黄 虬复眼的深伪瞳. 上图左下的图 6 应为图 9

这种现象同样可以从两种复眼的深伪瞳观察中得到证实。中央的光点(对应于感杆 7 末 端像的叠加)呈现一明亮的光玨, 而外周光点（对应于感杆 1-6 末端像的叠加）已成为一模糊 的“环”围绕在中央光点像的周围，或已消失. 这表明在强光适应之后，感杆 $1-6$ 的光通直径 已被“关闭”起来(图 8, 10). 
在这种情况下, 在某一方向上视觉信息的接收仅由第二亚视觉系统来完成, 与暗适应状态 下相比较,改善了对更小像点的分辨率。

讨 论

1. 两个亚视觉系统与两种不同的瞕孔机制 两个亚视觉系统的概念是以光学和解剖学 的研究为依据的 ${ }^{[5]}$. 本篇研究工作可能提供了一个补充的证据, 即两个亚视觉系统还具有不 同的瞳孔机制. 光诱发的色素移动主要出现在感受器细胞 1-6 中, 但仅在较少的感受器细胞 7 中出现了色素移动. 这个结果与我们的电镜观察是一致的. 我们 ${ }^{[6]}$ 的电镜观察表明感受器 细胞 1-6 的色素颗粒位置与明暗适应状态有关, 而仅在某些感受器细胞 7-8 中色素颗粒与 明暗适应状态有关系.

2. 家蝉与侐共虹复眼的光通年自动控制的区别 由视色素吸收光来控制色素颗粒的移 动在不同种类昆虫复眼中得到证明 ${ }^{[7]}$. 将家蝇与憎黄虹的瞳孔机制加以比较可以看出：图 1 所示接收视觉信息的模式在憎黄虹复眼中未观察到. 这个事实表明家蝇复眼光通量的控制范 围比憎黄虹复眼的宽. 这可能与昆虫的行为有密切关系, 家蝇既可以在弱光中活动又能在明 亮的阳光和强光下活动, 而憎黄虬只活动在夏季中午强光下.

\section{考文献}

[ 1 ] Kirschfeld, K., Exp. Brain Res., 3 (1967), 248-270.

[ 2 ] Scholes, J., Kybernetik., 6 (1969), 149-162.

[ 3 ] Campos-Ortega, J. and Strausfeld, N. J., Z. Zellforsch, 124 (1972), 561-585.

[4] 郭爱克等,生理学报, 34 (1982), 143-149.

[ 5 ] Kirschfeld, K. and Franceschini, N., Kybernetik., 5 (1968), 47-52.

[6] 吴卫国等,生物化学与生物物理学报, 15 (1983), 557-560.

[ 7 ] Stavenga, D. G. et al., J. Comp. Physiol., 129 (1979), 199-205. 